Article

\title{
Effect of Polycyclic Compounds Fillers on Electrical Treeing Characteristics in XLPE with DC-Impulse Voltage
}

\author{
Lewei Zhu ${ }^{1,2}$, Boxue $\mathrm{Du}^{2, *}$, Hongna $\mathrm{Li}^{1}$ and Kai Hou ${ }^{2}$ \\ 1 Maritime College, Tianjin University of Technology, Tianjin 300384, China \\ 2 Key Laboratory of Smart Grid of Education Ministry, School of Electrical and Information Engineering, \\ Tianjin University, Tianjin 300072, China \\ * Correspondence: duboxue@tju.edu.cn; Tel.: +86-22-2740-5477
}

Received: 27 June 2019; Accepted: 16 July 2019; Published: 18 July 2019

check for updates

\begin{abstract}
Electrical tree is an important factor in the threat of the safety of cross-linked polyethylene (XLPE) insulation, eventually leading to the electrical failure of cables. Polycyclic compounds have the potential to suppress electrical treeing growth. In this paper, three types of polycyclic compounds, 2-hydroxy-2-phenylacetophenone, 4-phenylbenzophenone, and 4,4'-difluorobenzophenone are added into XLPE, denoted by A, B, and C. Electrical treeing characteristics are researched with DC-impulse voltage at 30,60 , and $90^{\circ} \mathrm{C}$, and the trap distribution and carrier mobility are characterized. It has been found that although three types of polycyclic compounds can all suppress the electrical tree propagation at different voltages and temperatures, the suppression effect of these polycyclic compounds with the same DC-impulse polarity is worse than with the opposite polarity. As the temperature increases, the suppression effect becomes weak. The energy level and deep trap density are the largest in XLPE-A composite, leading to a decrease in the charge transportation and resulting in the suppression of electrical treeing growth. Experimental results reveal that the polycyclic compound A has great application prospects in high voltage direct current (HVDC) cables.
\end{abstract}

Keywords: electrical tree; XLPE; polycyclic compound; DC-impulse voltage; temperature; trap distribution

\section{Introduction}

Cross-linked polyethylene (XLPE) is wildly used in HVDC cables as the insulation material. Electrical tree degradation is an important issue to deteriorate overall insulation level, eventually leading to the electrical failure of cables [1-3]. Researchers have tried many ways to improve the electrical tree breakdown resistance of high voltage (HV) cables, including material blending modification, nanoparticle modification, and polycyclic compound modification [4-6]. Results showed that polycyclic compound had an excellent function of suppressing electrical treeing in polymeric insulating material $[7,8]$. The America Dow Chemical Company studied the effects of a series of siloxane polycyclic compounds containing pendant aromatic groups on the growth characteristics of electrical tree. It was found that the aromatic ring side groups are indispensable groups for suppressing electrical tree [9]. It was also found that aromatic ketones and diketones had great effects on inhibiting electrical treeing growth in XLPE and polyethylene (PE) $[5,10]$. Although much research has been carried out on the suppression effect of polycyclic compounds on electrical tree growth, the relationship between polycyclic compounds, charges, trapping levels, and electrical treeing is still unclear.

Research presented a lot of methods to analyze the electrical treeing process. The acoustic emission method and artificial neural networks were used in the detection of the treeing process [11,12]. In addition, imaging techniques such as transmission electron microscope (TEM), scanning electron 
microscope (SEM), or X-ray computed tomography (XCT) were used to reveal the more complete representation of the electrical treeing phenomenon [13]. Electrical treeing is a kind of cumulative breakdown which is also associated with the charge movement and trap distribution [14,15]. In the process of electron trapping and recombination, the hot electrons gain energy, impact, and destroy the molecular chains of polymer, forming the new electrical tree channel $[16,17]$. The deep trap level can capture mobile hot electrons, resulting in the decrease of the internal free charge [18]. However, little research has been done on the relationship between electrical tree and trap distribution in the XLPE/polycyclic compound composite.

In the DC transmission system, due to the on and off operations of power electronic devices, impulse overvoltage occurs. The lightning events and operating conditions may also cause lightning and operating overvoltage [19-21]. These impulse voltages are superimposed on the rated DC voltage to produce the DC-impulse voltage that affects the insulation electrical tree degradation process [22,23]. The electrical initiation and treeing characteristics in epoxy resin and polypropylene (PP) with DC-impulse voltage were studied, respectively [24,25]. Results revealed that the electrical treeing characteristics with DC-impulse voltage was different from those with DC voltage, and the polarity of impulse voltage had a significant effect on the electrical initiation and growth characteristics. However, at present, research on the effect of polycyclic compound on electrical tree suppression mostly focuses on AC voltage, and the electrical tree dependence on polycyclic compounds with DC-impulse voltage still needs to be studied. In addition, due to the heat generated by the large current, during the operation of HVDC cables, cables operate under high temperature conditions for a long time [26]. The maximum long-term design temperature of XLPE cables is generally $90{ }^{\circ} \mathrm{C}$, and the operating temperature is usually around $50-60^{\circ} \mathrm{C}$ [27]. It was found that high temperature affected the charge movement and partial discharge characteristics in the insulation, thus affecting the electrical treeing process $[28,29]$. However, most studies on polycyclic compounds are carried out at room temperature, and the effect of high temperature on polycyclic compounds still needs to be further studied.

In this paper, XLPE is employed as the polymer matrix, and three types of polycyclic compounds with the content of $0.5 \%$ are added into the XLPE. The electrical treeing properties of XLPE/ polycyclic compound composites are researched with DC-impulse voltage at 30,60 and $90{ }^{\circ} \mathrm{C}$. In addition, the trap distribution and carrier mobility behaviors are also studied to further reveal the mechanism of polycyclic compounds fillers on electrical treeing growth.

\section{Experiment}

\subsection{Test Samples and Electrode Arrangement}

This paper selects three types of polycyclic compounds. The polycyclic compound 2-hydroxy-2phenylacetophenone is denoted by A, which is produced by J\&K Scientific Ltd. The polycyclic compound 4-phenylbenzophenone is denoted by $\mathrm{B}$, which is produced by Shanghai Macklin Biochemical Co., Ltd. The polycyclic compound 4,4'-difluorobenzophenone is denoted by C, which is produced by J\&K Scientific Ltd. The molecular structures of these polycyclic compounds are shown in Figure 1. The neat XLPE was supplied by Borealis Company. At $110^{\circ} \mathrm{C}$, we put the appropriate amount of XLPE into the mixer and mixed for $3 \mathrm{~min}$. Then we weighed an amount of $0.5 \mathrm{wt} \%$ polycyclic compound and added it to the internal mixer. We then mixed for $10 \mathrm{~min}$ to make it evenly dispersed in XLPE. Then we used the flat vulcanizing machine and the special mold to make the needle-plate electrode samples [30]. The distance between the tip and the ground electrode was $2 \pm 0.1 \mathrm{~mm}$. The needle electrode diameter and curvature radius were $300 \mu \mathrm{m}$ and $3 \mu \mathrm{m}$, respectively. 


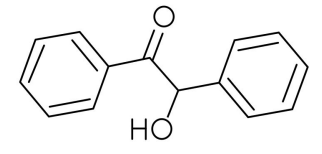

(a) 2-hydroxy-2-phenylacetophenone

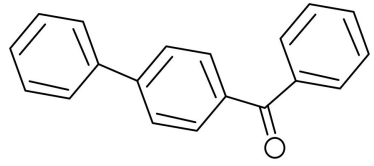

(b) 4-phenylbenzophenone

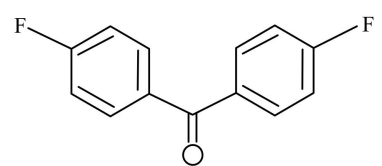

(c) 4,4'-difluorobenzophenone

Figure 1. Molecular structures of polycyclic compounds.

\subsection{Experimental Apparatus and Procedure}

Figure 2 shows the schematic diagram of the experimental setup. The electrical tree experiment was carried out in the high temperature environment experimental platform. The sample was placed in a heat-resistant glass cylinder with dimethyl silicone oil, which could effectively prevent surface flashover of the sample during the experiment. In addition, silicone oil could also fill the surface of the sample to increase the transparency of the sample, improving the clarity of the electrical tree observation. The high temperature environment was provided by the resistance wires on both sides of the heat-resistant glass cylinder, and the maximum operating temperature was $200^{\circ} \mathrm{C}$. The experimental temperature was set to 30,60 , and $90^{\circ} \mathrm{C}$ to make a temperature gradient. After the temperature reached the set temperature during the experiment, the sample was allowed to stand in the incubator for $10 \mathrm{~min}$ to ensure that the temperature of the material was consistent with the environment. The DC-impulse voltage was generated by the DC-impulse power source, which consisted of a DC power source and impulse power source [31]. The DC voltage was applied at a rate of $1 \mathrm{kV} / \mathrm{s}$. After $1 \mathrm{~min}$, the impulse voltage was applied at a rate of $1 \mathrm{kV} / \mathrm{s}$. In order to reduce the error, each set of experiments was repeated 20 times. Because the electrical treeing initiation and breakdown phenomenon had a great relationship with the relative polarity of the impulse voltage with DC-impulse voltage [25], the electrical treeing characteristics with $-25 \mathrm{kV}$ DC and $\pm 35 \mathrm{kV}$ impulse voltage were measured to analyze the suppression effect of polycyclic compounds with DC-impulse voltage. The impulse voltage frequency was $400 \mathrm{~Hz}$. The equivalent circuit of the experimental configuration is shown in Figure A1 in our Appendix A. The electrical tree imaging system included a computer, microscope unit, and a cold light source. The microscope unit consisted of an objective lens, an eyepiece, and a charge-coupled device (CCD). The CCD was a high-resolution imaging device. The camera multiplier was $1 \times$ and the highest resolution was $1024 \times 768$ pixels. The three objective magnifications were $4 \times, 10 \times, 40 \times$, and the eyepiece magnification was $10 \times$. The accumulated damage was used to analyze the electrical treeing characteristics. The accumulated damage refers to the number of pixels in the area covered by the electrical tree, which can be used to characterize the damage area of electrical tree to insulating materials, and to describe the development trend of electrical tree in space [29,32]. The accumulated damage was calculated using Matlab language. The specific calculation method was divided into three steps. The first step was to take a photo of the entire electrical branch with a pixel value of $500 \times 500$ pixels. In the second step, the image was subjected to filtering binarization to obtain a black and white image. The third step was to count the total number of pixels in the black area of the image. The value obtained is the accumulated damage value of the electrical tree.

The surface potential decay (SPD) technique is an effective method for measuring trap distribution behaviors [33]. The surface charge test system consisted of an HVDC power supply, a pin-gate-plate electrode system, a TREK type surface potentiometer (including a Kelvin type vibrating probe), and a constant temperature and humidity chamber. The vertical distance from the tip of the needle electrode to the gate electrode, and the vertical distance from the gate electrode to the surface of the sample were both $5 \mathrm{~mm}$. The Kelvin vibrating probe was fixed with an epoxy holder with a vertical distance of $3 \mathrm{~mm}$ from the surface of the specimen. Charge was injected onto the surface of the sample for a charge time of $10 \mathrm{~min}$. After the corona was over, we moved the center of the sample quickly below the surface potential measurement probe. The experimental temperature was set to 30,60 , and $90{ }^{\circ} \mathrm{C}$ with a relative humidity of $\sim 20 \%$. In this paper, the distribution of trap energy level (Et) 
and the trap density $(\mathrm{N} t)$ are calculated to analyze the electrical property behaviors [34]. The carrier mobility was also calculated [35], which can obtain the characteristics of charge transportation.

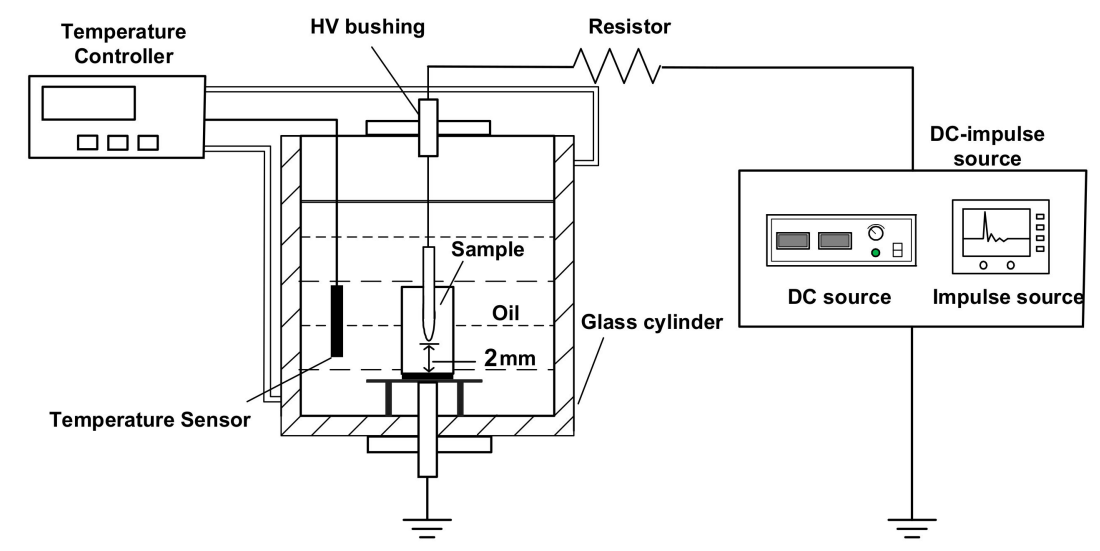

Figure 2. Schematic diagram of experimental setup.

\section{Results}

\subsection{Electrical Tree Degradation}

\subsubsection{Tree Structure}

The structure of electrical tree in polymer is related to certain combined factors: voltage waveform, temperature, and polymer fillers [36-38]. Table 1 shows the electrical tree structure distribution at $1 \mathrm{~min}$. Figure 3 shows the electrical tree structures of the neat XLPE and polycyclic compound modified samples. Figure $3 \mathrm{a}, \mathrm{b}$ show the compared electrical tree structures with $-25 \mathrm{kV}$ DC and $+35 \mathrm{kV}$ impulse voltages (the opposite polarity). Figure $3 \mathrm{c}$,d show the compared electrical tree structures with $-25 \mathrm{kV}$ DC and $-35 \mathrm{kV}$ impulse voltages (the same polarity). The treeing times for both are $1 \mathrm{~min}$ for the convenience of comparison. In order to save space, only modified samples with a type A polycyclic compound were selected for comparison with neat XLPE samples. The electrical tree structures of XLPE-B and XLPE-C are shown in Figure A2 in our Appendix A. It can be seen that the electrical tree structures of neat XLPE samples are not affected by the temperature and the DC-impulse voltage waveform, which are branch trees. These results are consistent with the results in the literature [22], of which the electrical tree structures of PP samples are not affected by the DC-impulse voltage waveform at room temperature. After the addition of the polycyclic compound, the electrical tree structure changes, which are related to the polycyclic compound type. For XLPE-A samples, with $-25 \mathrm{kV}$ DC and $+35 \mathrm{kV}$ impulse voltage (the opposite polarity), the tree structures change to bush trees at 30 and $60{ }^{\circ} \mathrm{C}$ and it is double tree at $90^{\circ} \mathrm{C}$. With $-25 \mathrm{kV}$ DC and $-35 \mathrm{kV}$ impulse voltage (the same polarity), the tree structures change to bush trees at $30^{\circ} \mathrm{C}$. However, they are still branch trees at 60 and $90^{\circ} \mathrm{C}$. For XLPE-B and XLPE-C, the tree structures are double tree at $30^{\circ} \mathrm{C}$. However, they are still branch trees at 60 and $90^{\circ} \mathrm{C}$.

Table 1. Tree structure distribution at $1 \mathrm{~min}$.

\begin{tabular}{ccccccc}
\hline $\begin{array}{c}\text { DC } \\
(\mathbf{k V})\end{array}$ & $\begin{array}{c}\text { Pulse } \\
\mathbf{( k V )}\end{array}$ & $\begin{array}{c}\text { Temperature } \\
\left({ }^{\circ} \mathbf{C}\right)\end{array}$ & XLPE & XLPE-A & XLPE-B & XLPE-C \\
\hline & & 30 & Branch & Bush & Bush-branch & Bush-branch \\
& +35 & 60 & Branch & Bush & Branch & Branch \\
-25 & & 90 & Branch & Bush-branch & Branch & Branch \\
& & 30 & Branch & Bush & Bush-branch & Bush-branch \\
& -35 & 60 & Branch & Branch & Branch & Branch \\
& & 90 & Branch & Branch & Branch & Branch \\
\hline
\end{tabular}



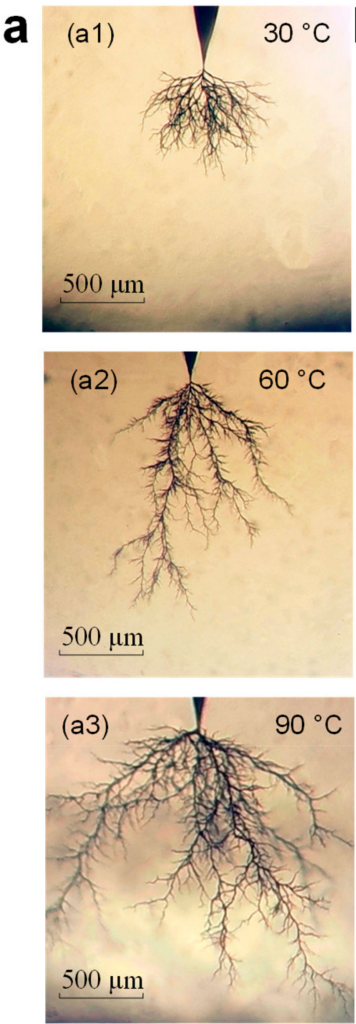

(a) $-25 \mathrm{kV} \mathrm{DC}+35 \mathrm{kV}$ pulse (b) XLPE
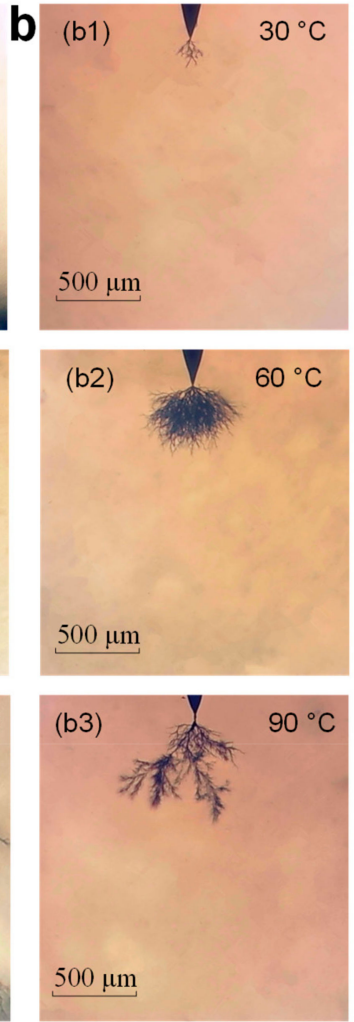

XLPE-A
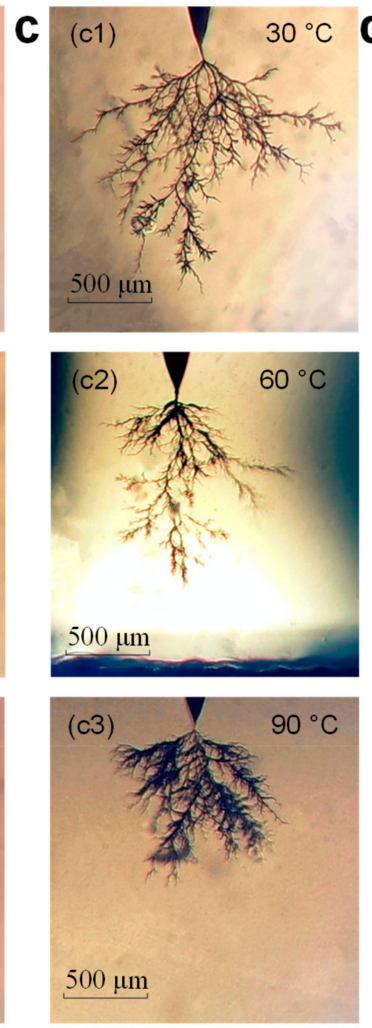

(c) $-25 \mathrm{kV}$ DC-35 kV pulse (d) XLPE
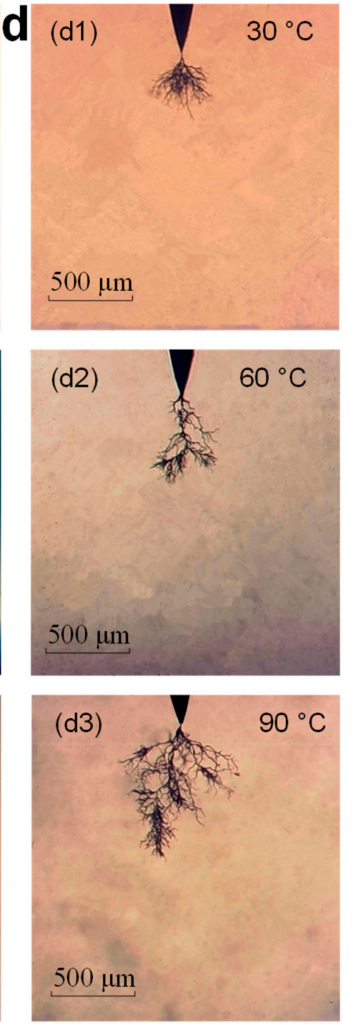

(d) $-25 \mathrm{kV}$ DC-35 kV pulse XLPE-A

Figure 3. The electrical tree structures of the neat cross-linked polyethylene (XLPE) and XLPE-A composite.

\subsubsection{Electrical Treeing Characteristics with Opposite Polarity DC-Impulse Voltage}

Figure 4 shows the electrical treeing characteristics of a representative electrical tree with opposite polarity DC-impulse voltage; Figure 4a is the relationship of the electrical tree length and the treeing time; Figure $4 \mathrm{~b}$ is the relationship of the accumulated damage and the treeing time. The treeing voltage is $+35 \mathrm{kV}$ impulse superimposed $-25 \mathrm{kV}$ DC voltage, of which the impulse voltage polarity is opposite to the DC voltage polarity. The treeing time is $60 \mathrm{~s}$, and the experimental temperatures are respectively 30,60 , and $90^{\circ} \mathrm{C}$. The electrical tree length of XLPE-A composite is $167 \mu \mathrm{m}$ at $30^{\circ} \mathrm{C}$ in $60 \mathrm{~s}$ and is reduced by $74.8 \%$ compared to the neat XLPE; the accumulated damage of XLPE-A is $0.5 \times 10^{3}$ pixels at $30^{\circ} \mathrm{C}$ in $60 \mathrm{~s}$ and is reduced by $97.6 \%$ compared to the neat XLPE. The electrical tree length of XLPE-A is reduced by $69.9 \%$ at $60^{\circ} \mathrm{C}$ in $60 \mathrm{~s}$ compared to the neat XLPE and the accumulated damage is reduced by $64 \%$. At $90{ }^{\circ} \mathrm{C}$, the electrical tree length of XLPE-A is reduced by $68.5 \%$ and the accumulated damage is reduced by $59.6 \%$. For XLPE-B composites, the electrical tree length and accumulated damage are respectively reduced by $51.7 \%$ and $87.9 \%$ at $30{ }^{\circ} \mathrm{C}, 51.4 \%$ and $36.4 \%$ at $60{ }^{\circ} \mathrm{C}$, and $50.3 \%$ and $31.6 \%$ at $90{ }^{\circ} \mathrm{C}$ in $60 \mathrm{~s}$. For XLPE-C composites, the electrical tree length and accumulated damage is respectively reduced by $34.3 \%$ and $41.7 \%$ at $30{ }^{\circ} \mathrm{C}, 32.2 \%$ and $19.1 \%$ at $60{ }^{\circ} \mathrm{C}$, and $30.8 \%$ and $26.3 \%$ at $90^{\circ} \mathrm{C}$. The experimental results reveal that the three type of polycyclic compounds all inhibit the length and accumulated damage of the electrical tree. Among them, the polycyclic compound A has the best effect, the type $B$ is second, and the type $C$ has the worst effect. It can be concluded that as the temperature increases, although the three polycyclic compounds still inhibit the growth of electrical trees, the effect of inhibition becomes weak. 


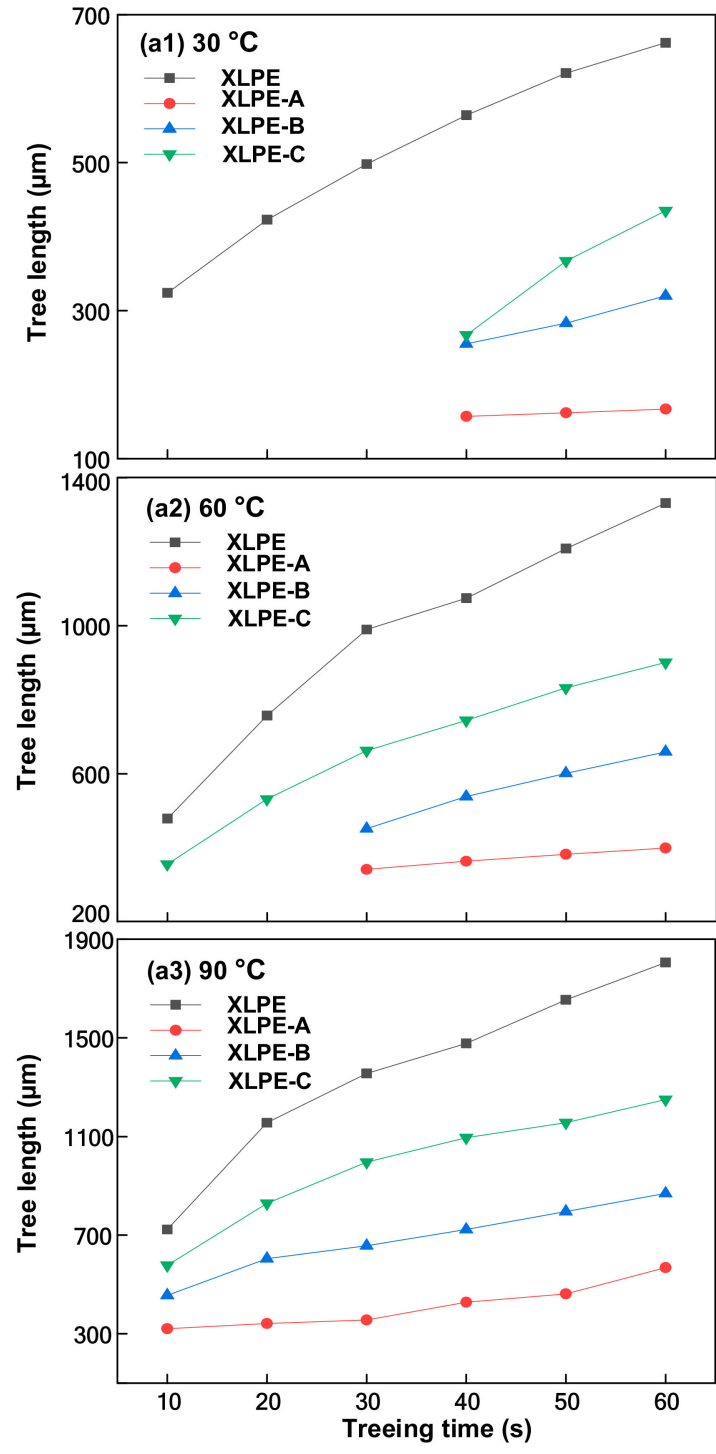

(a) The relationship of the tree length and the treeing time
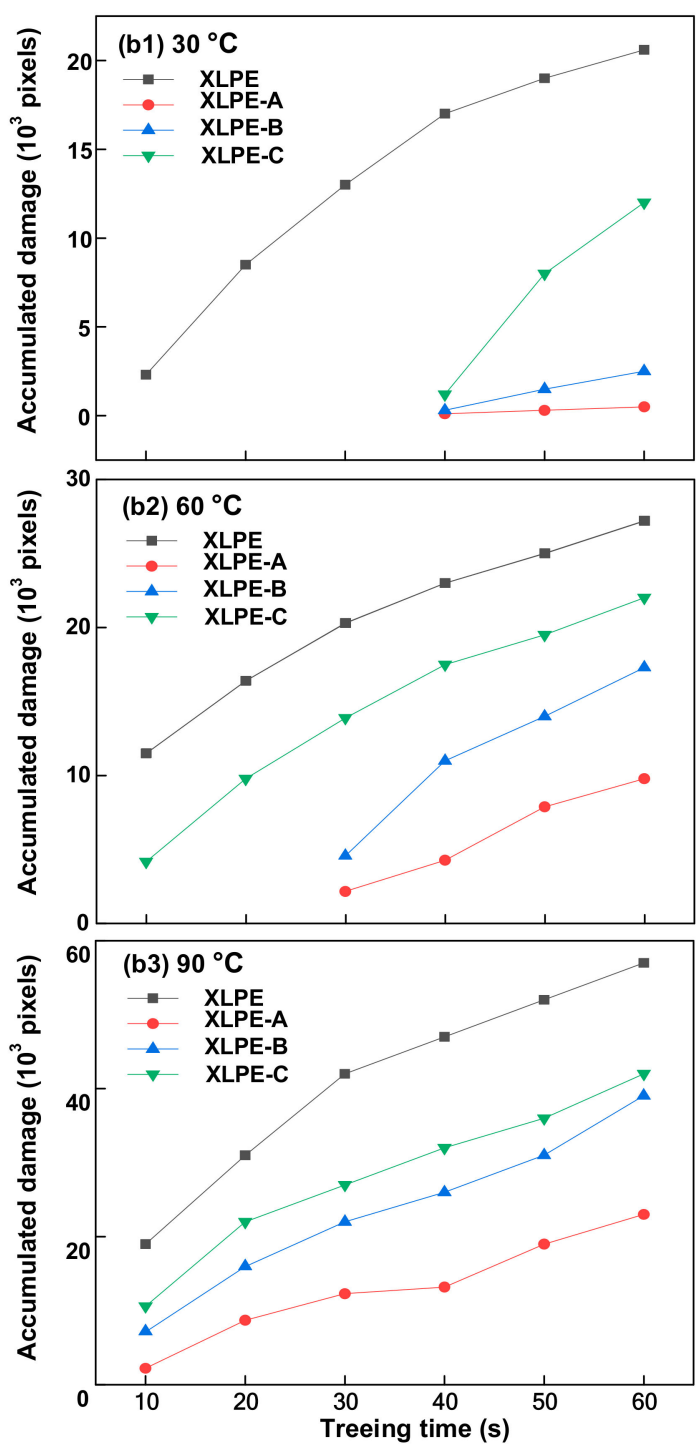

(b) The relationship of the accumulated damage and the treeing time

Figure 4. Electrical treeing characteristics with opposite polarity DC-impulse voltage.

\subsubsection{Electrical Treeing Characteristics with the Same Polarity DC-Impulse Voltage}

Figure 5 shows the electrical treeing characteristics of a representative electrical tree with the same polarity DC-impulse voltage; Figure 5a is the relationship of the electrical tree length and the treeing time; Figure $5 b$ is the relationship of the accumulated damage and the treeing time. The treeing voltage is $-35 \mathrm{kV}$ impulse superimposed $-25 \mathrm{kV}$ DC voltage, of which the impulse voltage polarity is the same as the DC voltage polarity. The electrical tree length of XLPE-A is $379 \mu \mathrm{m}$ at $30^{\circ} \mathrm{C}$ in $60 \mathrm{~s}$ and is reduced by $71.9 \%$ compared to the neat XLPE; The accumulated damage of XLPE-A is $9.1 \times 10^{3}$ pixels at $30^{\circ} \mathrm{C}$ in $60 \mathrm{~s}$ and is reduced by $72.1 \%$ compared to the neat XLPE. The electrical tree length of XLPE-A is reduced by $57.3 \%$ at $60{ }^{\circ} \mathrm{C}$ in $60 \mathrm{~s}$ compared to the neat XLPE and the accumulated damage is reduced by $63.2 \%$. At $90{ }^{\circ} \mathrm{C}$, the electrical tree length of XLPE-A is reduced by $22.9 \%$ and the accumulated damage is reduced by $46.8 \%$. For XLPE-B composites, the electrical tree length and accumulated damage are respectively reduced by $46.7 \%$ and $44.8 \%$ at $30{ }^{\circ} \mathrm{C}, 20.5 \%$ and $32.5 \%$ at $60{ }^{\circ} \mathrm{C}$, and $14 \%$ and $29.1 \%$ at $90{ }^{\circ} \mathrm{C}$. For XLPE-C composites, the electrical tree length and accumulated damage are respectively reduced by $31.9 \%$ and $26.4 \%$ at $30{ }^{\circ} \mathrm{C}, 23.8 \%$ and $16.9 \%$ at $60{ }^{\circ} \mathrm{C}$, and $3 \%$ and $10.2 \%$ at $90{ }^{\circ} \mathrm{C}$. The three polycyclic compounds all inhibit the growth of the electrical tree, and the polycyclic 
compound A has the best effect, which is consistent with the results that have an opposite polarity DC-impulse voltage. The effect of temperature on the polycyclic compound is still the same as that with the opposite polarity. As the temperature increases, the suppression effect of the three polycyclic compounds becomes weak. It can be concluded that the suppression effect of the three types of polycyclic compounds with the same polarity is worse than with the opposite polarity.

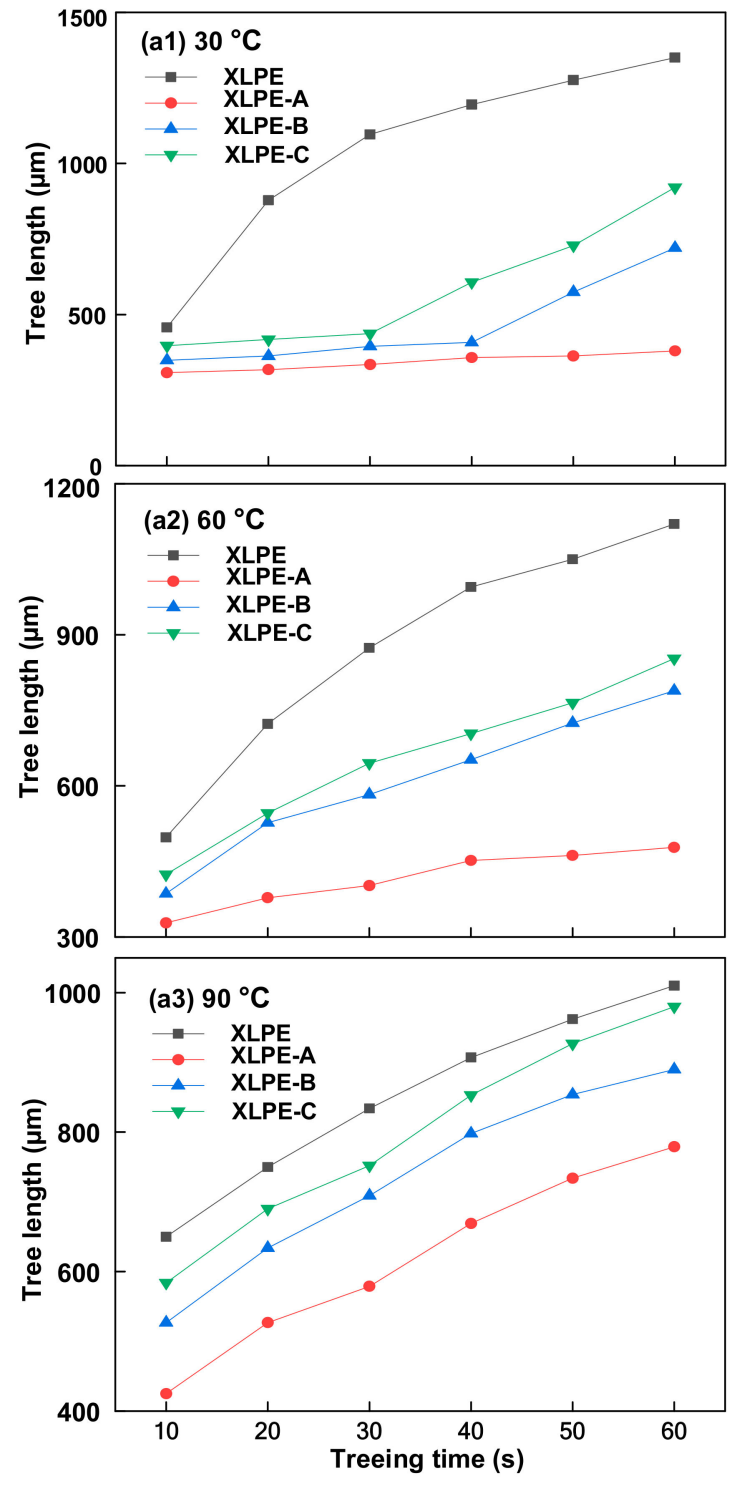

(a) The relationship of the tree length and the treeing time
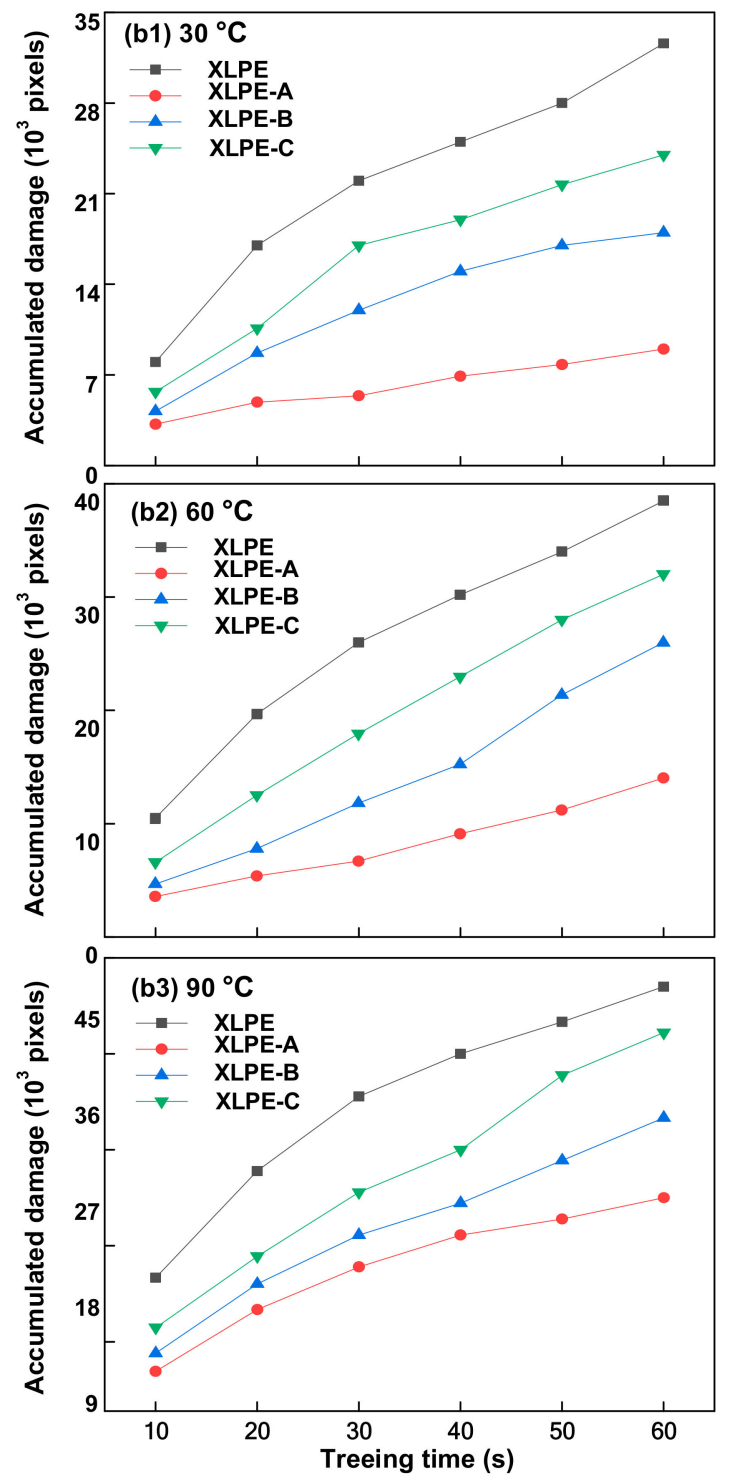

(b) The relationship of the accumulated damage and the treeing time

Figure 5. Electrical treeing characteristics with the same polarity DC-impulse voltage.

\subsection{Trap Distribution and Carrier Mobility Behaviors}

There are many trap levels in the forbidden band of polymer materials. The formation of trap levels is complicated, and many factors affect the trap level, including molecular chain end groups, branches, amorphous regions and crystallization regions, polarizing groups, impurities, etc., as well as various physical chemistry effects that cause structural defects in materials [39]. After the polycyclic compound is added to the XLPE, the trap distribution and the carrier mobility behaviors change accordingly. In this section, the variation of the trap distribution and the carrier mobility behaviors of representative XLPE/polycyclic compounds at different temperatures are obtained, as shown in Figure 6. Figure 6(a1) compares the trap distribution behaviors of different samples at $30{ }^{\circ} \mathrm{C}$. It can be seen that 
the trap distribution of the neat XLPE sample exhibits a double peak shape, for which a peak appears at a shallower trap level, and a peak appears at a deeper trap level. However, there is only one deep trap peak of the XLPE/polycyclic compound composites, indicating that the number of shallow traps is small. It can be seen from Table 2 that the deep trap depth of the neat XLPE sample is $0.88 \mathrm{eV}$ at $30^{\circ} \mathrm{C}$. After adding the polycyclic compound, the deep trap depth is among $0.93 \mathrm{eV}$ to $0.97 \mathrm{eV}$ at $30^{\circ} \mathrm{C}$. It can be concluded that the deep trap level of the XLPE/polycyclic compounds composites increases, and the corresponding trap density increases, indicating that the addition of the polycyclic compounds introduces deep traps inside the XLPE sample. Among them, trap depth of the XLPE-A composite is the largest, XLPE-B is second largest, and trap depth of XLPE-C is the smallest. Figure 6(b1) compares the carrier mobility of different samples at $30{ }^{\circ} \mathrm{C}$. The neat XLPE sample has a carrier mobility of $12.5 \times 10^{-14} \mathrm{~m}^{2} \mathrm{~V}^{-1} \mathrm{~s}^{-1}$, the XLPE-A has a carrier mobility of $0.5 \times 10^{-14} \mathrm{~m}^{2} \mathrm{~V}^{-1} \mathrm{~s}^{-1}$, the XLPE-B has a carrier mobility of $2 \times 10^{-14} \mathrm{~m}^{2} \mathrm{~V}^{-1} \mathrm{~s}^{-1}$, and the XLPE-C has a carrier mobility of $5.6 \times 10^{-14} \mathrm{~m}^{2} \mathrm{~V}^{-1} \mathrm{~s}^{-1}$. It is more difficult for charges to escape from deep traps than shallow traps [35]. After the polycyclic compound is added, the depth of the deep trap becomes larger, and the charge trapped by the deep trap is more difficult to transfer from the deep trap to the ground electrode, so that the carrier mobility of samples becomes smaller [11]. Figure 6(a2,a3) compare the trap distribution behaviors of different samples at 60 and $90^{\circ} \mathrm{C}$. The neat XLPE has a shallow trap depth of $0.85 \mathrm{eV}$ and a deep trap depth of $0.91 \mathrm{eV}$ at $60^{\circ} \mathrm{C}$. After adding $\mathrm{A}, \mathrm{B}$, and $\mathrm{C}$ polycyclic compounds, only deep traps are measured and the depths are $0.97,0.94$, and $0.93 \mathrm{eV}$, respectively. The neat XLPE has a shallow trap depth of $0.91 \mathrm{eV}$ and a deep trap depth of $1 \mathrm{eV}$ at $90^{\circ} \mathrm{C}$. After adding three types of polycyclic compounds, A, $\mathrm{B}$, and $\mathrm{C}$, the shallower trap depths are $0.98,0.95$, and $0.92 \mathrm{eV}$, respectively. The deeper trap depths are $1.02,1.02$ and $1.01 \mathrm{eV}$, respectively. Figure $6(\mathrm{~b} 2, \mathrm{~b} 3)$ compare the carrier mobility behaviors of different samples at 60 and $90^{\circ} \mathrm{C}$. The carrier mobility of XLPE is the largest, $24 \times 10^{-14} \mathrm{~m}^{2} \mathrm{~V}^{-1} \mathrm{~s}^{-1}$ and $100 \times 10^{-14} \mathrm{~m}^{2} \mathrm{~V}^{-1} \mathrm{~s}^{-1}$, respectively. The carrier mobility of XLPE-A is the smallest, $0.9375 \times 10^{-14}$ $\mathrm{m}^{2} \mathrm{~V}^{-1} \mathrm{~s}^{-1}$ and $13.65 \times 10^{-14} \mathrm{~m}^{2} \mathrm{~V}^{-1} \mathrm{~s}^{-1}$, respectively. It can be concluded that the addition of the polycyclic compounds increases the trap depth and the corresponding trap density of the XLPE and reduces the carrier mobility. Among them, the XLPE-A composite has the deepest trap depth, trap density, and the smallest carrier mobility.

Table 2. Cross-linked polyethylene (XLPE) and its polycyclic compounds composites trap depth.

\begin{tabular}{|c|c|c|c|}
\hline Type & Temperature $\left({ }^{\circ} \mathrm{C}\right)$ & Shallow Trap Depth / (eV) & Deep Trap Depth / (eV) \\
\hline \multirow{4}{*}{ XLPE } & 30 & 0.81 & 0.88 \\
\hline & 60 & 0.85 & 0.91 \\
\hline & 90 & 0.91 & 1 \\
\hline & 30 & / & 0.98 \\
\hline \multirow{3}{*}{ XLPE-A } & 60 & 1 & 0.97 \\
\hline & 90 & 0.98 & 1.02 \\
\hline & 30 & / & 0.93 \\
\hline \multirow{3}{*}{ XLPE-B } & 60 & / & 0.94 \\
\hline & 90 & 0.95 & 1.02 \\
\hline & 30 & / & 0.9 \\
\hline \multirow[t]{2}{*}{ XLPE-C } & 60 & / & 0.93 \\
\hline & 90 & 0.92 & 1.01 \\
\hline
\end{tabular}



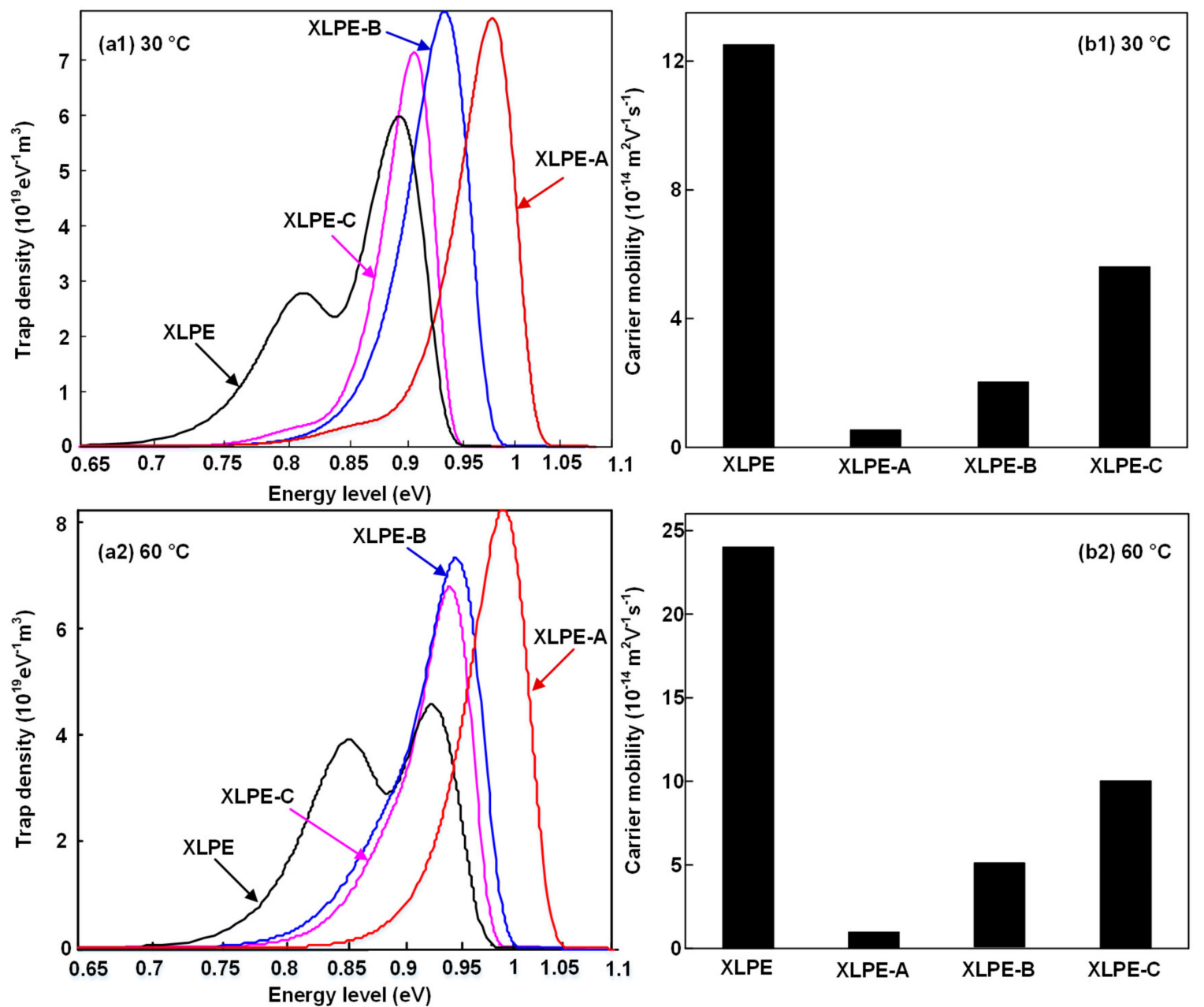

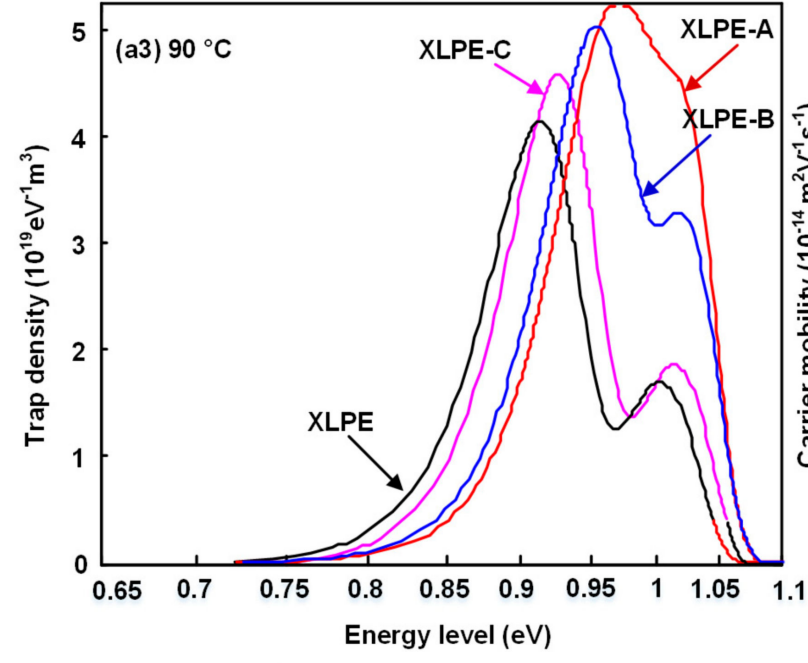

(a) Trap distribution behaviors

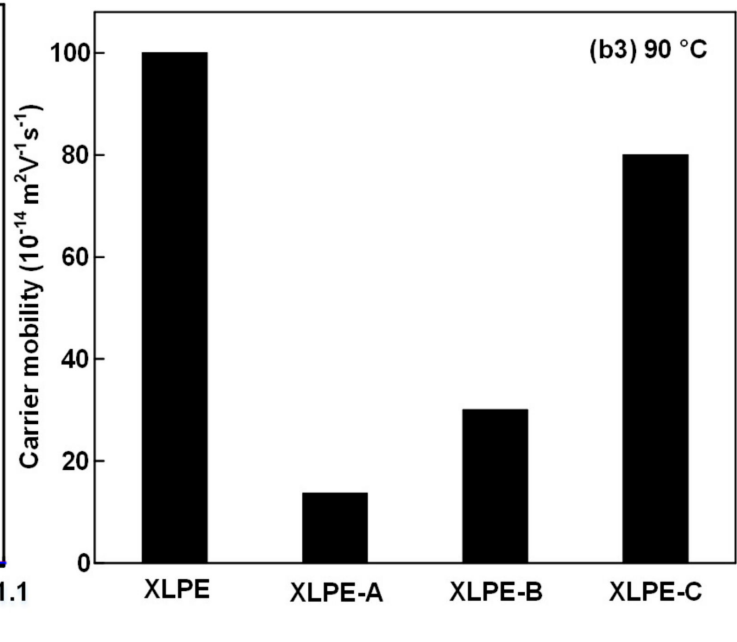

(b) Carrier mobility behaviors

Figure 6. Trap distribution and carrier mobility behaviors of XLPE and its polycyclic compounds composites.

\section{Discussion}

\subsection{Mechanism of Polycyclic Compounds Fillers Inhibiting Electrical Treeing Growth}

The growth process of the electrical tree with the DC-impulse voltage is closely related to the hot electrons motion and trap distribution [40]. After the addition of the polycyclic compound, the trap depth and density of samples increase significantly. The traps enhance the charge trapping ability 
of the needle tip and easily forms the same polarity charge accumulation to weaken the external electric field, resulting in a decrease in the injected charge amount [41]. At the same time, with the deep trap level and the trap density increasing, the internal charge trapping of the sample enhances, resulting in a decrease in the internal free charge of the sample. For the growth of the electrical tree, the charge injection process is suppressed and the free charge inside the sample is reduced. Therefore, the molecular chain breaking process is suppressed, and the electrical tree deterioration resistance of the XLPE/ polycyclic compounds composites is improved. In addition, in the process of electrical tree growth, some of the electrical tree channels are carbonized, and the carbonization channel delivers charges as a conductive current to the end of the channel, enhancing the electric field strength [42]. The deeper trap captures the transport charges in the carbonized electrical tree channels, reducing the electric field strength at the end of the channel, thereby decreasing the growth of the electrical tree [29]. The carrier migration process is closely related to the trap distribution of the composite material. The free charge may be captured by the local state (trap) during the extended state migration process. The charge transfer and exchange process between the extended state and the local state affects the migration characteristics of carriers [41]. After the addition of the polycyclic compound, the carrier mobility is reduced, and the carrier mobility of XLPE-A is the smallest. The deep trap energy level increases, leading to the increase of trap barrier to overcome for charge trapping. The deep trap density increases, leading to a decrease of the charge average free travel and energy obtained from migration, increasing the probability of charge trapping, and leading to a decrease in mobility. Therefore, the internal collision ionization probability of the composite material is reduced, leading to the improvement in the resistance to electrical tree.

\subsection{Electrical Tree Dependence on Polycyclic Compounds with DC-Impulse Voltage}

It can be seen from the results in Section 3.1 that the effect of the polycyclic compound is related to the polarity of the DC-impulse voltage, and the suppression effect of the polycyclic compound with the opposite polarity is better than with the same polarity. When $-35 \mathrm{kV}$ impulse is superimposed on $-25 \mathrm{kV}$ DC voltage, after the DC voltage is applied, electrons are accumulated at the needle tip. After the impulse voltage is applied, a large number of electrons are injected into polymer over a short period of time to push accumulated charges to move. During the process of charge trapping, as the state of charge changes from high energy to low energy state, excess energy is transferred to other charges, making them hot electrons, destroying the XLPE molecular chain, and causing growth of the electrical tree. When $+35 \mathrm{kV}$ impulse is superimposed on $-25 \mathrm{kV}$ DC voltage, and after the polarity of the voltage changes, part of the positive charge is injected and the positive and negative charges neutralize to generate energy, which accelerates the growth of the electrical tree [43]. In addition, as the polarity of the voltage changes from negative to positive, the electrons change from the same-polar space charge to the hetero-polar space charge, causing electric field distortion, aggravating partial discharge, causing molecular chain breakage, and accelerating electrical tree growth [44]. The mechanism of electrical tree growth with different polarities is different, which results in different effects of polycyclic compounds with different polarities. With the opposite DC-impulse polarity voltage, and after the polycyclic compound is added, on the one hand, the electric field distortion caused by the polarity change is reduced due to the decrease of the injected charges; on the other hand, since free charges inside the sample are reduced, the energy generated by the positive and negative charges is reduced. Therefore, the polycyclic compound effect with the opposite polarity is better.

\subsection{Electrical Tree Dependence on Polycyclic Compounds at Different Temperatures}

Electrical treeing is an electro-thermal aging phenomenon, which is a comprehensive process including charge motion, partial discharge, local high pressure, and local high temperature. The hot electrons accelerate in the free volume, which impacts the molecular chain of the polymer and accelerates the formation of low-density regions. Charges collide with ionization in low-density regions, releasing energy to destroy more molecular chains and forming micropores. Subsequent 
discharges then occur in the micropores. Partial discharge produces local temperature rise in a short time. When the ambient temperature plus local temperature rise is greater than the local softening temperature of the insulating material ( $\left.\Delta T_{\text {ambient temperature }}+\Delta T_{\text {discharge temperature }}>T_{\text {softening temperature }}\right)$, local thermal breakdown will occur, and the air gaps form cracks along the applied field direction [45]. Under the action of charged particles, the XLPE molecular chains are broken rapidly and proceed to decompose and gasify. With these gases generated in a short time, the gas pressure in the micropores and cracks increases rapidly, resulting in the material around the micropores or cracks to undergo an expansion stress. Under the action of this stress, the micropores and cracks rapidly expand toward the amorphous region where the mechanical strength is weak, resulting in the growth of the electrical tree. As the temperature increases, on the one hand, the carrier mobility increases, the ionization probability increases, and the polycyclic compound's ability to capture hot electrons is relatively reduced; on the other hand, the local thermal breakdown increases, and the influence of hot electrons on the growth characteristics of the electrical tree is relatively reduced. Therefore, the effect of the polycyclic compound decreases with temperature increase.

\section{Conclusions}

In this paper, three different types of polycyclic compounds were chosen to prepare the XLPE/polycyclic compounds composites. The effects of these polycyclic compounds on the tree structure and electrical treeing characteristics with DC-impulse voltage were studied at 30,60 , and $90^{\circ} \mathrm{C}$. Their trap distribution and carrier mobility behaviors were also investigated. The experimental results reveal that polycyclic compound A has great application prospects in HVDC cables. The following are our main conclusions:

(1) The addition of the polycyclic compound changes the electrical tree structure, which is related to the type of the polycyclic compound, the temperature and the relative polarity of DC and impulse voltage.

(2) The electrical treeing characteristics are related to the type of polycyclic compounds. The three type of polycyclic compounds all inhibit the length and accumulated damage of the electrical tree with DC-impulse voltages at 30,60 , and $90^{\circ} \mathrm{C}$. The energy level and trap density are the largest in XLPE-A composite, decreasing the charge transport, and leading to the suppression of the electrical treeing growth, improving the lifetime of XLPE. The polycyclic compound A has great application prospects in HVDC cables.

(3) The effect of the polycyclic compound is related to the relative polarity of the applied DC-impulse voltage. Although three types of polycyclic compounds can suppress the electrical tree propagation at different DC-impulse voltages, the suppression effect with the same polarity is worse than with the opposite polarity, which is related to the difference in the mechanism of electrical tree growth with different impulse polarities.

(4) The effect of the polycyclic compound is related to the temperature. With the temperature increasing, the suppression effect to electrical treeing growth of polycyclic compounds decreases. However, the three types of polycyclic compounds can still suppress the electrical treeing growth at 30,60 , and $90^{\circ} \mathrm{C}$, which can improve the lifetime of XLPE cables.

Author Contributions: L.Z. and B.D. came up with the idea and designed the structure of the paper. L.Z. finished the experiments and wrote the manuscript. H.L. and K.H. analyzed the data and provided analytical theory for electrical breakdown.

Acknowledgments: This work is supported by the National Key Research and Development Program of China (Grant 2016YFB0900701); the Chinese National Natural Science Foundation under the Grant 51537008.

Conflicts of Interest: The authors declare no conflict of interest. 


\section{Appendix A}

Figure $\mathrm{A} 1$ shows the equivalent circuit of the experimental configuration. Figure A2 shows the electrical tree structures of XLPE-B and XLPE-C.

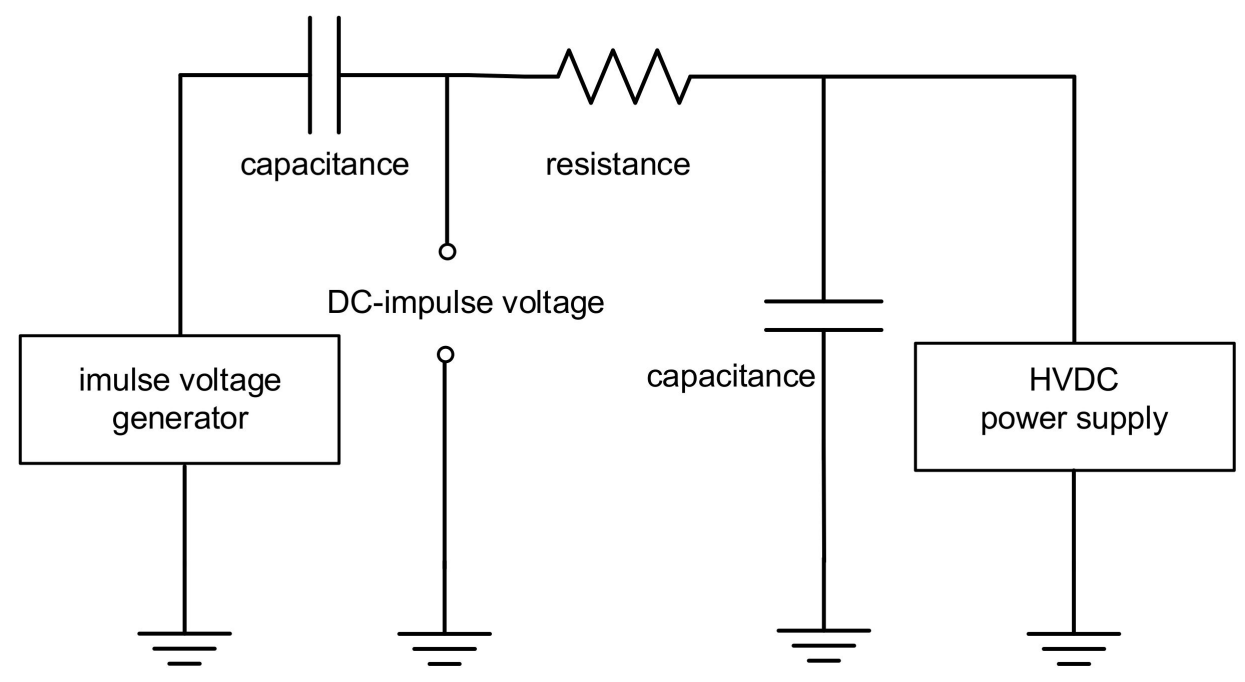

Figure A1. The equivalent circuit of the experimental configuration.

a
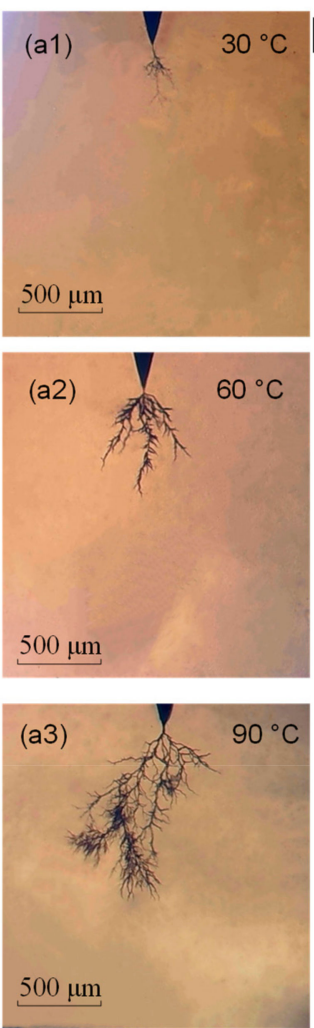
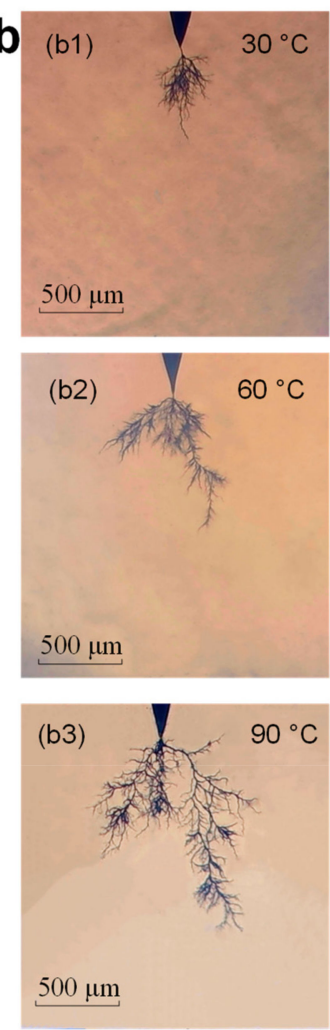
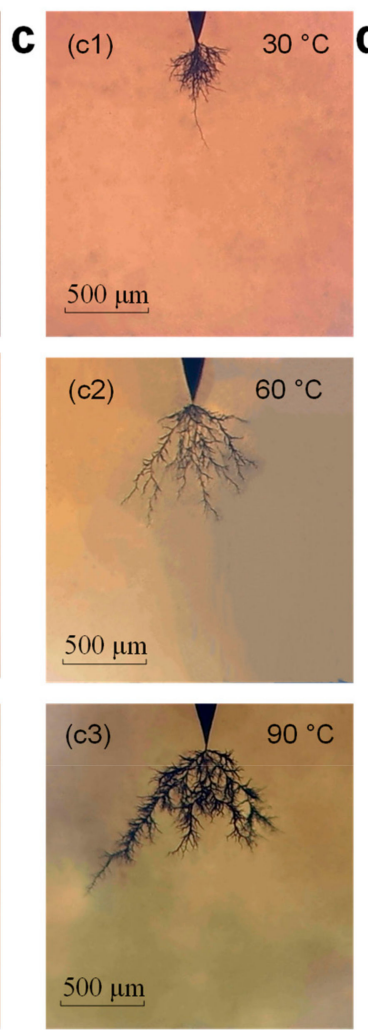

(c) -25 kV DC-35 kV pulse (d) -25 kV DC-35 kV pulse
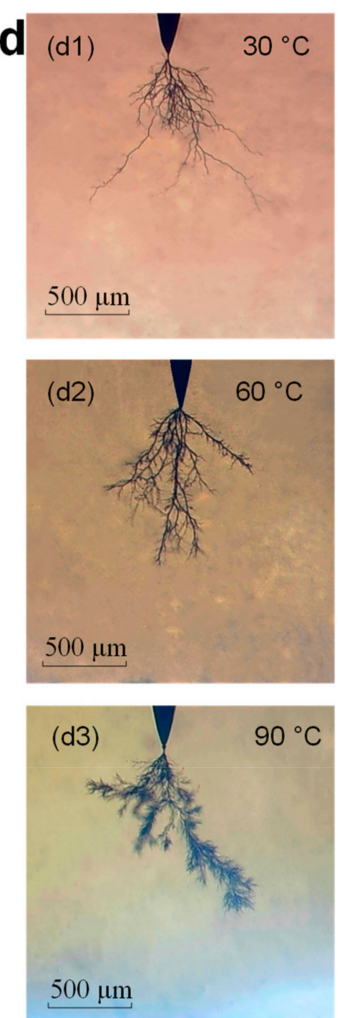

XLPE-C

(a) $-25 \mathrm{kV} D C+35 \mathrm{kV}$ pulse (b) $-25 \mathrm{kV} \mathrm{DC}+35 \mathrm{kV}$ pulse XLPE-B XLPE-C

Figure A2. The electrical tree structures of XLPE-B and XLPE-C composite. 


\section{References}

1. Danikas, M.G.; Tanaka, T. Nanocomposites-a review of electrical treeing and breakdown. IEEE Trans. Dielectr. Electr. Insul. 2009, 25, 19-24. [CrossRef]

2. Saito, Y.; Fukuzawa, M.; Nakamura, H. On the mechanism of tree initiation. IEEE Trans. Electr. Insul. 1977, 1, 31-34. [CrossRef]

3. Han, T.; Du, B.X.; Ma, T.T.; Wang, F.Y.; Gao, Y.; Lei, Z.P.; Li, C.Y. Electrical tree in HTV silicone rubber with temperature gradient under repetitive pulse voltage. IEEE Access 2019, 7, 41250-41260. [CrossRef]

4. Jiang, C.; Hou, Y.X.; Yu, J.Z.; Wei, Z.J.; Chen, X.R.; Zhou, H. Electrical treeing of polyethylene blends with/without voltage stabilizer. In Proceedings of the IEEE 2018 12th International Conference on the Properties and Applications of Dielectric Materials, Xi'an, China, 20-24 May 2018; pp. 266-269.

5. Kisin, S.; Doelder, J.D.; Eaton, R.F. Quantum mechanical criteria for choosing appropriate voltage stabilization additives for polyethylene. Polym. Degrad. Stab. 2009, 94, 171-175. [CrossRef]

6. Han, T.; Du, B.X.; Su, J.G.; Gao, Y.; Xing, Y.Q.; Fang, S.C.; Li, C.Y.; Lei, Z.P. Inhibition effect of graphene nanoplatelets on electrical degradation in silicone rubber. Polymers 2019, 11, 968. [CrossRef] [PubMed]

7. Yamano, Y. Roles of polycyclic compounds in increasing breakdown strength of LDPE film. IEEE Trans. Electr. Insul. 2006, 13, 773-781. [CrossRef]

8. Jarvid, M.; Johansson, A.; Kroon, R.; Bjuggren, J.M.; Wutzel, H.; Englund, V.; Gubanski, S.; Andersson, M.R.; Muller, C. A new application area for fullerenes: Voltage stabilizers for power cable insulation. Adv. Mater. 2015, 27, 897-902. [CrossRef]

9. Vincent, G.A. Anti-Treeing Additives. U.S. Patent 4,840,983, 20 June 1989.

10. Jarvid, M.; Johansson, A.; Bjuggren, J.M.; Wutzel, H.; Englund, V.; Gubanski, S.; Muller, C.; Andersson, M.R. Tailored side-chain architecture of benzil voltage stabilizers for enhanced dielectric strength of cross-linked polyethylene. J. Polym. Sci. Part B Polym. Phys. 2014, 52, 1047-1054. [CrossRef]

11. Opydo, W.; Dobrzycki, A. Detection of electric tree of solid dielectrics with the method of acoustic emission. Electr. Eng. 2012, 94, 37-48. [CrossRef]

12. Dobrzycki, A.; Mikulski, S.; Opydo, W. Using ANN and SVM for the detection of acoustic emission signals accompanying epoxy resin electrical treeing. Appl. Sci. 2019, 9, 1523. [CrossRef]

13. Schurch, R.; Rowland, S.M.; Bradley, R.S.; Withers, P.J. Imaging and analysis techniques for electrical trees using X-ray computed tomography. IEEE Trans. Dielectr. Electr. Insul. 2014, 21, 53-63. [CrossRef]

14. Li, S.T.; Min, D.M.; Wang, W.W.; Chen, G. Linking traps to dielectric breakdown through charge dynamics for polymer nanocomposites. IEEE Trans. Dielectr. Electr. Insul. 2016, 23, 2777-2785. [CrossRef]

15. Tanaka, Y.; Ohnuma, N.; Katsunami, K. Effects of crystallinity and electron mean-free-path on dielectric strength of low-density polyethylene. IEEE Trans. Dielectr. Electr. Insul. 1991, 26, 258-265. [CrossRef]

16. Shimizu, N.; Laurent, C. Electrical tree initiation. IEEE Trans. Dielectr. Electr. Insul. 1998, 5, 651-659. [CrossRef]

17. Kao, K.C. New theory of electrical discharge and breakdown in low-mobility condensed insulators. J. Appl. Phys. 1984, 55, 752-755. [CrossRef]

18. Wang, W.W.; Min, D.M.; Li, S.T. Understanding the conduction and breakdown properties of polyethylene nanodielectrics: Effect of deep traps. IEEE Trans. Dielectr. Electr. Insul. 2016, 23, 564-572. [CrossRef]

19. Hingorani, N.G. Transient overvoltage on a bipolar HVDC overhead line caused by DC line faults. IEEE Trans. Power Appar. Syst. 1970, PAS-89, 592-610. [CrossRef]

20. Lu, W.X.; Ooi, B.T. DC overvoltage control during loss of converter in multiterminal voltage-source converter-based HVDC (M-VSC-HVDC). IEEE Trans. Power Deliv. 2003, 18, 915-920.

21. Zhou, C.H.; Wang, P. A study of temporary overvoltage at HVDC rectifier stations. In Proceedings of the 2011 IEEE Electrical Power and Energy Conference, Winnipeg, MB, Canada, 3-5 October 2011; pp. 211-215.

22. Hagiwara, M.; Akagi, H. Control and experiment of pulsewidth-modulated modular multilevel converters. IEEE Trans. Power Electron. 2009, 24, 1737-1746. [CrossRef]

23. Murata, Y.; Katakai, S.; Kanaoka, M. Impulse breakdown superposed on ac voltage in XLPE cable insulation. IEEE Trans. Dielectr. Electr. Insul. 1996, 3, 361-365. [CrossRef] 
24. Du, B.X.; Su, J.G.; Xue, J.S. Tree growth characteristics of epoxy resin in LN2 under DC superimposed pulse voltage. IEEE Trans. Appl. Superconduct. 2018, 28,1-5. [CrossRef]

25. Zhu, L.W.; Du, B.X.; Su, J.G.; Han, T.; Danikas, M.G. Electrical treeing initiation and breakdown phenomenon in polypropylene under DC and pulse combined voltages. IEEE Trans. Dielectr. Electr. Insul. 2019, 26, 202-210. [CrossRef]

26. Bozzo, R.; Gemme, C.; Guastavino, F. The effects of temperature on the tree growth phenomena and relevant PD. In Proceedings of the IEEE Conference on Electrical Insulation and Dielectric Phenomena, Virginia Beach, VA, USA, 22-25 October 1995; pp. 69-72.

27. Shimizu, N.; Shibata, Y.; Ito, K.; Imai, K.; Nawata, M. Electrical tree at high temperature in xlpe and effect of oxygen. In Proceedings of the IEEE Conference on Electrical Insulation and Dielectric Phenomena, Victoria, BC, Canada, 15-18 October 2000; pp. 329-332.

28. Wang, Y.; Li, G.; Wu, J. Effect of temperature on space charge detrapping and periodic grounded DC tree in cross-linked polyethylene. IEEE Trans. Dielectr. Electr. Insul. 2017, 23, 3704-3711. [CrossRef]

29. Du, B.X.; Zhu, L.W.; Han, T. Effect of ambient temperature on electrical treeing and breakdown phenomenon of polypropylene with repetitive pulse voltage. IEEE Trans. Dielectr. Electr. Insul. 2017, 24, 2216-2224. [CrossRef]

30. Du, B.X.; Zhu, L.W.; Han, T. Effect of low temperature on electrical treeing of polypropylene with repetitive pulse voltage. IEEE Trans. Dielectr. Electr. Insul. 2016, 23, 1915-1923. [CrossRef]

31. Han, T.; Du, B.X.; Su, J.G. Electrical tree initiation and growth in silicone rubber under combined dc-pulse voltage. Energies 2018, 11, 764. [CrossRef]

32. Chen, G.; Tham, C. Electrical treeing characteristics in XLPE power cable insulation in frequency range between 20 and 500 Hz. IEEE Trans. Dielectr. Electr. Insul. 2009, 16, 179-188. [CrossRef]

33. Zhou, F.S.; Li, J.Y.; Liu, M.X.; Min, D.M.; Li, S.T.; Xia, R. Characterizing traps distribution in LDPE and HDPE through isothermal surface potential decay method. IEEE Trans. Dielectr. Electr. Insul. 2016, 23, 1174-1182. [CrossRef]

34. Li, J.Y.; Zhou, F.S.; Min, D.M.; Li, S.T.; Xia, R. The energy distribution of trapped charges in polymers based on isothermal surface potential decay model. IEEE Trans. Dielectr. Electr. Insul. 2015, 22, 1723-1732. [CrossRef]

35. Zhou, F.S.; Li, J.Y.; Yan, Z.M.; Zhang, X.; Yang, Y.Q.; Liu, M.X.; Min, D.M.; Li, S.T. Investigation of charge trapping and detrapping dynamics in LDPE, HDPE and XLPE. IEEE Trans. Dielectr. Electr. Insul. 2016, 23, 3742-3751. [CrossRef]

36. Chen, X.R.; Hu, L.B.; Xu, Y.; Cao, X.L.; Gubanski, S.M. Investigation of temperature effect on electrical trees in XLPE cable insulation. In Proceedings of the Electrical Insulation and Dielectric Phenomena, Montreal, QC, Canada, 14-17 October 2012; pp. 612-615.

37. Liu, Y.; Cao, X.L. Electrical tree initiation in XLPE cable insulation by application of DC and impulse voltage. IEEE Trans. Dielectr. Electr. Insul. 2013, 20, 1691-1698.

38. Ashcraft, A.C.; Eichhorn, R.M.; Shaw, R.G. Laboratory studies of treeing in solid dielectrics and voltage stabilization of polyethylene. In Proceedings of the IEEE International Conference on Electrical Insulation, Montreal, QC, Canada, 14-16 June 2016; pp. 213-218.

39. Du, B.X.; Han, C.L.; Li, J. Effect of voltage stabilizers on the space charge behavior of XLPE for HVDC cable application. IEEE Trans. Dielectr. Electr. Insul. 2019, 26, 34-42. [CrossRef]

40. Serra, S.; Tosatti, E.; Iarlori, S.; Scandolo, S.; Santoro, G. Interchain electron states in polyethylene. Phys. Rev. B 2000, 62, 4389-4393. [CrossRef]

41. Du, B.X.; Su, J.G.; Tian, M.; Han, T.; Li, J. Understanding trap effects on electrical treeing phenomena in EPDM/POSS composites. Sci. Rep. 2018, 8, 8481-8495. [CrossRef]

42. Zheng, X.Q.; Chen, G. Propagation Mechanism of Electrical Tree in XLPE Cable Insulation by Investigating a Double Electrical Tree Structure. IEEE Trans. Dielectr. Electr. Insul. 2008, 15, 800-807. [CrossRef]

43. Bamji, S.S.; Bulinski, A.T.; Densley, R.J. Degradation mechanism at XLPE/semicon interface subjected to high electrical stress. IEEE Trans. Dielectr. Electr. Insul. 1991, 26, 278-284. [CrossRef] 
44. Zhang, S.; Zhang, H.; Liu, P.; Peng, Z.R. Space charge characteristics of epoxy-based nanocomposites filled with graphene oxide. In Proceedings of the IEEE Conference on Electrical Insulation and Dielectric Phenomena, Toronto, ON, Canada, 16-19 October 2016; pp. 691-694.

45. Zhao, L.; Su, J.C.; Pan, Y.F.; Li, R.; Zheng, L.; Zhang, Y.; Wu, X.L.; Zhao, P.C. Calculation on heating effect due to void discharge in polymers in cumulative breakdown process. IEEE Trans. Dielectr. Electr. Insul. 2017, 24, 3113-3121. [CrossRef]

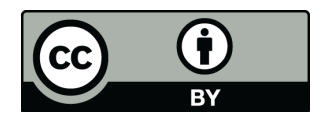

(C) 2019 by the authors. Licensee MDPI, Basel, Switzerland. This article is an open access article distributed under the terms and conditions of the Creative Commons Attribution (CC BY) license (http://creativecommons.org/licenses/by/4.0/). 